Submission ID: 43803

\title{
Geonavigation Using Petroinfotech Prosystem Software Is One of the Main Methods of Successfully Directing Directional Wells on the Shelf of the Caspian Sea
}

I. Khaliullov* (LUKOIL-Nizhnevolzhskneft), A. Alekseev (LUKOIL-Nizhnevolzhskneft), A. Shtun (LUKOIL-Nizhnevolzhskneft)

\section{SUMMARY}

Oil and Gas Condensate Field. V. Filanovsky is located in the northern part of the water area of the Caspian Sea. The deposit is confined to the anticlinal uplift, characterized by a series of burst faults of fault type. The initial geological model of the deposit is based on the interpretation of 3D seismic data and GIS data in 3 reference wells. The accuracy of the position of the roof of the target productive horizon in the planning of the first horizontal well was estimated at $+/-20$ m vertically, according to the structural constructs. Accumulated in 000 LUKOIL-Nizhnevolzhskneft drilling experience with the use of an integrated approach to the analysis of geological and geophysical information and decision making allows successful successful entry of complex horizontal wells. Implementation of these tasks requires an easy-to-use and mastering software covering all aspects of the planning of trajectories, posting and analysis of the results of horizontal drilling of trunks. An example of the use of PetroInfoTech ProSystem software with the posting of a doublebarrel horizontal well at the deposit is presented. V. Filanovsky. 
Геонавигация с применением ПО ПетроИнфоТех ПроСистем - одни из основных методов успешной проводки наклонно-направленных скважин на шельфе Каспийского моря.

И.Р. Халиуллов* (ООО «ЛУКОЙЛ-Нижневолжскнефть»), А.Г. Алексеев (ООО «ЛУКОЙЛНижневолжскнефть»), А.С. Штунь (ООО «ЛУКОЙЛ-Нижневолжскнефть»)

\section{Введение}

Нефтегазоконденсатное месторождение им. В. Филановского расположено в северной части акватории Каспийского моря. Месторождение приурочено к антиклинальному поднятию (рис.1), характеризующемуся серией разрывных нарушений сбросового типа. Основными продуктивными отложениями являются песчаные нижнемеловые горные породы неокомского надъяруса K1nc, мощность которых составляет 50-60 м. Первая очередь освоения месторождения была начата в 2016 году путем бурения горизонтальных скважин с морской платформы ЛСП-1. В дальнейшем планируется разработка месторождения с установкой второй буровой платформы ЛСП-2.

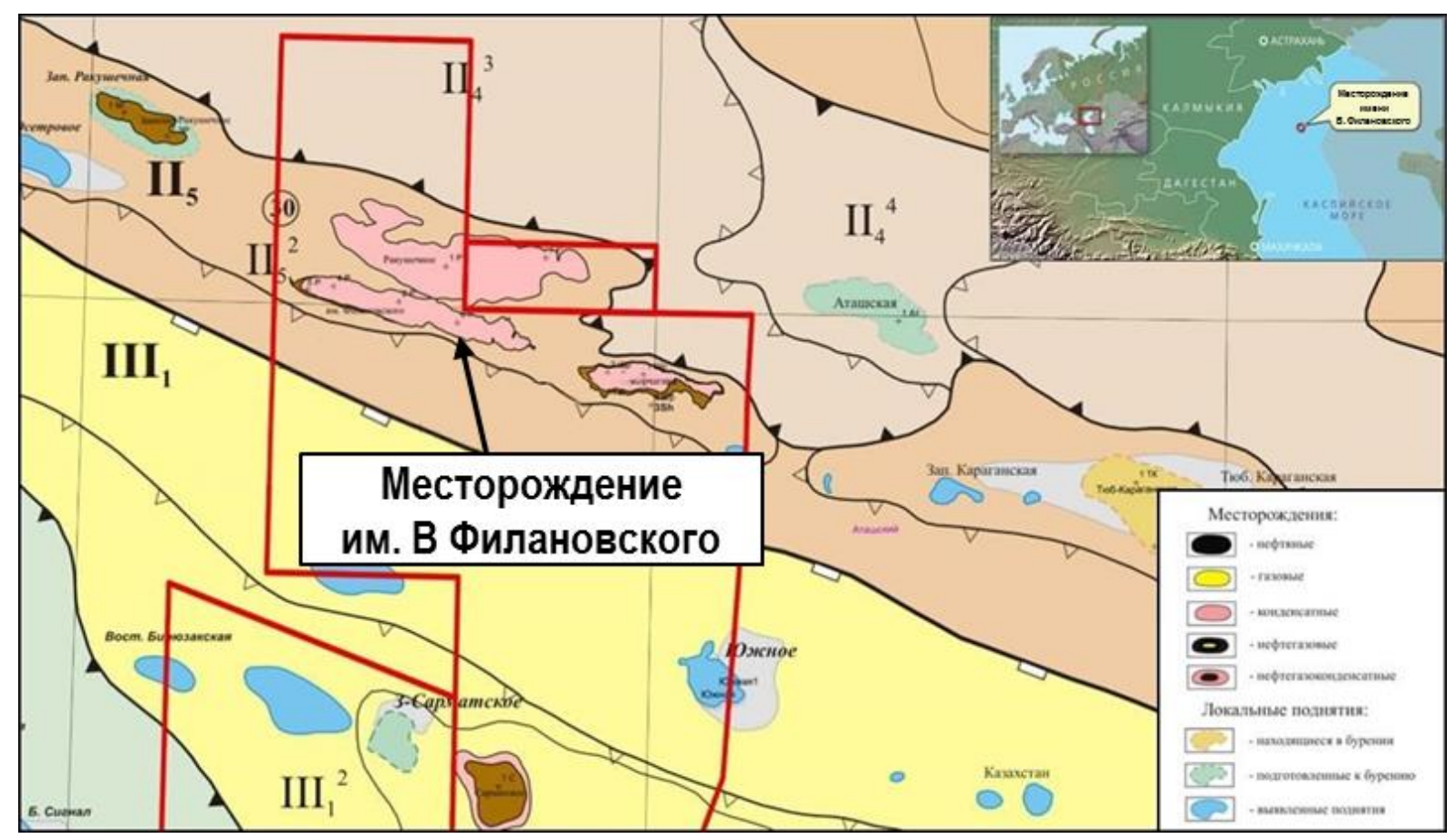

Рисунок 1. Общие сведения о месторождении им. В. Филановского (ПО ПетроИнфоТех ПроСистем).

Исходная геологическая модель месторождения основана на интерпретации данных 3D сейсморазведки и данных ГИС в 3-х опорных скважинах. Ввиду отсутствия широкоазимутальной сейсмической съемки и ограниченного фонда вертикальных скважин точность положения кровли целевого продуктивного горизонта при планировании первой горизонтальной скважины оценивалась в +/-20 м по вертикали, согласно структурным построениям.

\section{Применение ПО ПетроИнфоТех ПроСистем при разбуривании месторождения им. В.Филановского}

В реалиях интенсивного развития нефтегазодобывающей отрасли одним из необходимых условий успешного освоения месторождения на всех этапах является правильный выбор программного обеспечения, которое помогало бы достичь всех поставленных целей. 


\section{EAGE}

Проведение работ по геологическому сопровождению проводки скважин требует применения широкого комплекса исследований, направленных на изучение геологического строения месторождения. Наиболее качественно и эффективно выполнить геонавигационную проводку скважины возможно с использованием всего спектра геолого-геофизических данных.

Накопленный в ООО «ЛУКОЙЛ-Нижневолжскнефть» опыт бурения с использованием комплексного подхода к анализу геолого-геофизической информации и принятию решений позволяет выполнять успешную проводку сложных горизонтальных скважин. Реализация этих задач требует простого в использовании и в овладении программного обеспечения охватывающего все стороны процесса планирования траекторий, проводки и анализа результатов бурения горизонтальных стволов.

Представлен пример использования ПО ПетроИнфоТех ПроСистем при проводке двуствольной горизонтальной скважины на месторождении им. В. Филановского (рис.2).

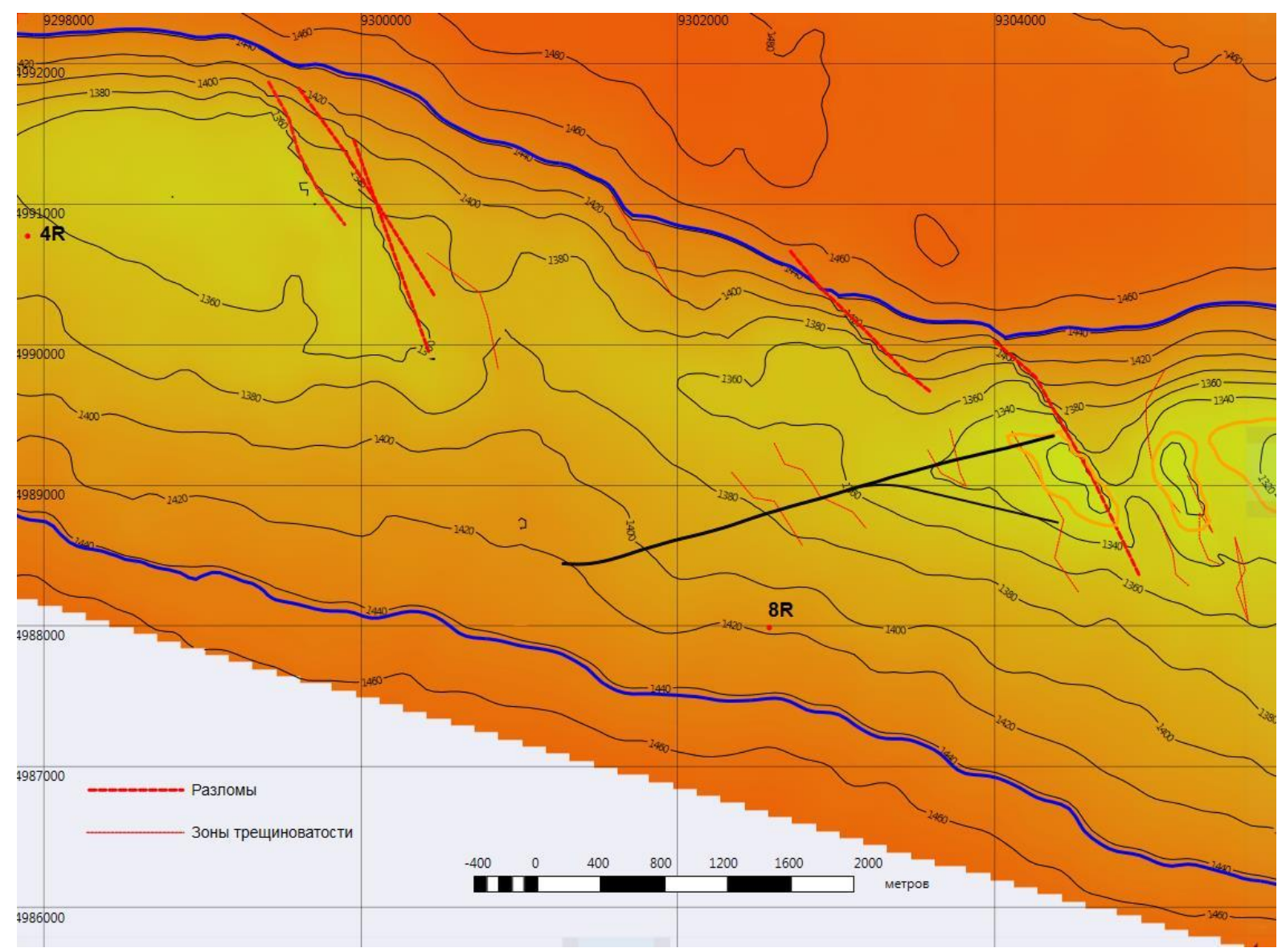

Рисунок 2. Структурная карта по кровле отложений неокома месторождения им. В. Филановского с двуствольной скважиной (ПО ПетроИнфоТех ПроСистем).

Целевыми интервалами скважины являлись первая, вторая, третья и четвертая пачки неокомского надъяруса. План бурения предполагал посадку эксплуатационной секции в подошвенной части аптских отложений, бурение горизонтальной секции с пересечением трех пачек и выполаживание в прикровельной части четвертой песчаной пачки неокомского надъяруса, а также вскрытие кровли юрских отложений. Важность вскрытия юрских отложений на заключительном этапе была обоснована необходимостью подтверждения геологического строения. 


\section{EAGE}

Общая длина основного ствола №1 скважины составляет 4092 м. Протяжённость горизонтальной секции скважины составила 1193 м с глубины башмака ОК - 2898 м по стволу (рис.3). Суммарная проходка по коллектору, по окончательному петрофизическому заключению, составляет 910,4 метра (до глубины наличия каротажа 4088 м), что соответствует 76\% от общей длины горизонтального участка скважины.

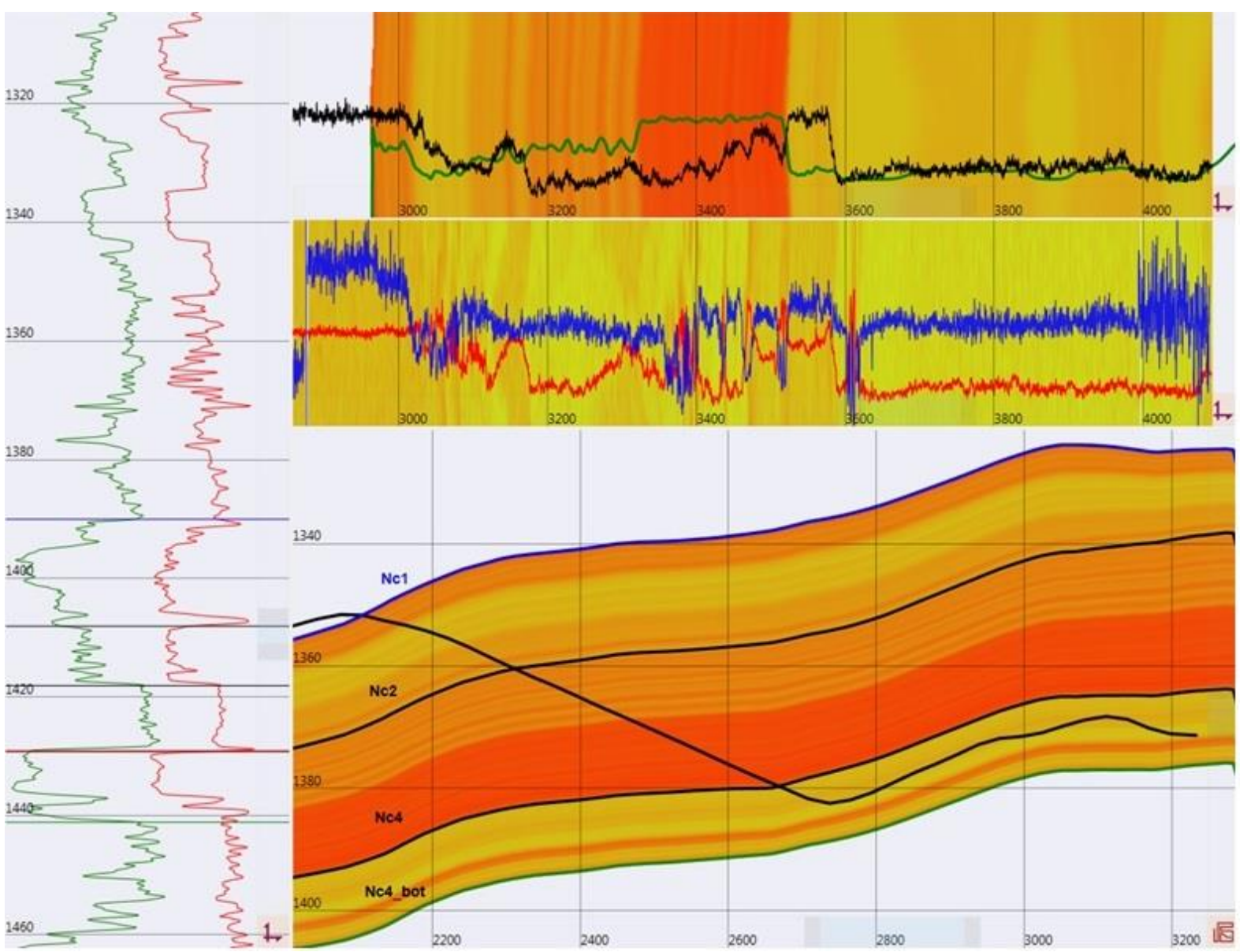

Рисунок 3. Разрез вдоль фактической траектории основного ствола 1. Распределение свойств по глинистости (ПО ПетроИнфоТех ПроСистем).

Общая длина основного ствола №2 скважины составляет 4102 м. Протяжённость горизонтальной секции скважины составила 1370 м с глубины башмака ОК - 2898 м по стволу (рис.4). Суммарная проходка по коллектору, по окончательному петрофизическому заключению, составляет 874,7 метров (до глубины наличия каротажа 4067.8 м), что соответствует $64 \%$ от общей длины горизонтального участка скважины.

В процессе бурения основного ствола №1 скважины, с целью выполнения всех поставленных задач скважины, траектория подвергалась корректировкам при бурении эксплуатационной секции 342.3 мм - 5 раз, при бурении горизонтальной секции 241.9 мм - 8 раз.

В процессе бурения основного ствола №2 скважины, вскрываемый разрез совпадал с обновленной структурной моделью на основании данных инверсии GeoSphere по первому стволу скважины. Однако с целью расположения ствола скважины в наиболее продуктивном коллекторе в ходе бурения было принято -8 корректировок.

При посадке эксплуатационной секции особую сложность представляла необходимость обеспечения интервала стабилизации в приподошвенной части аптских глин с зенитным углом менее $90^{\circ}$. В условиях малой изученности месторождения данная задача представлялась 


\section{EAGE}

особенно сложной. Предварительное моделирование было направлено на определение характера отклика инверсии GeoSphere на контрастных границах внутри аптских глин с целью определения угла залегания пласта на кровле пород неокомского надъяруса.

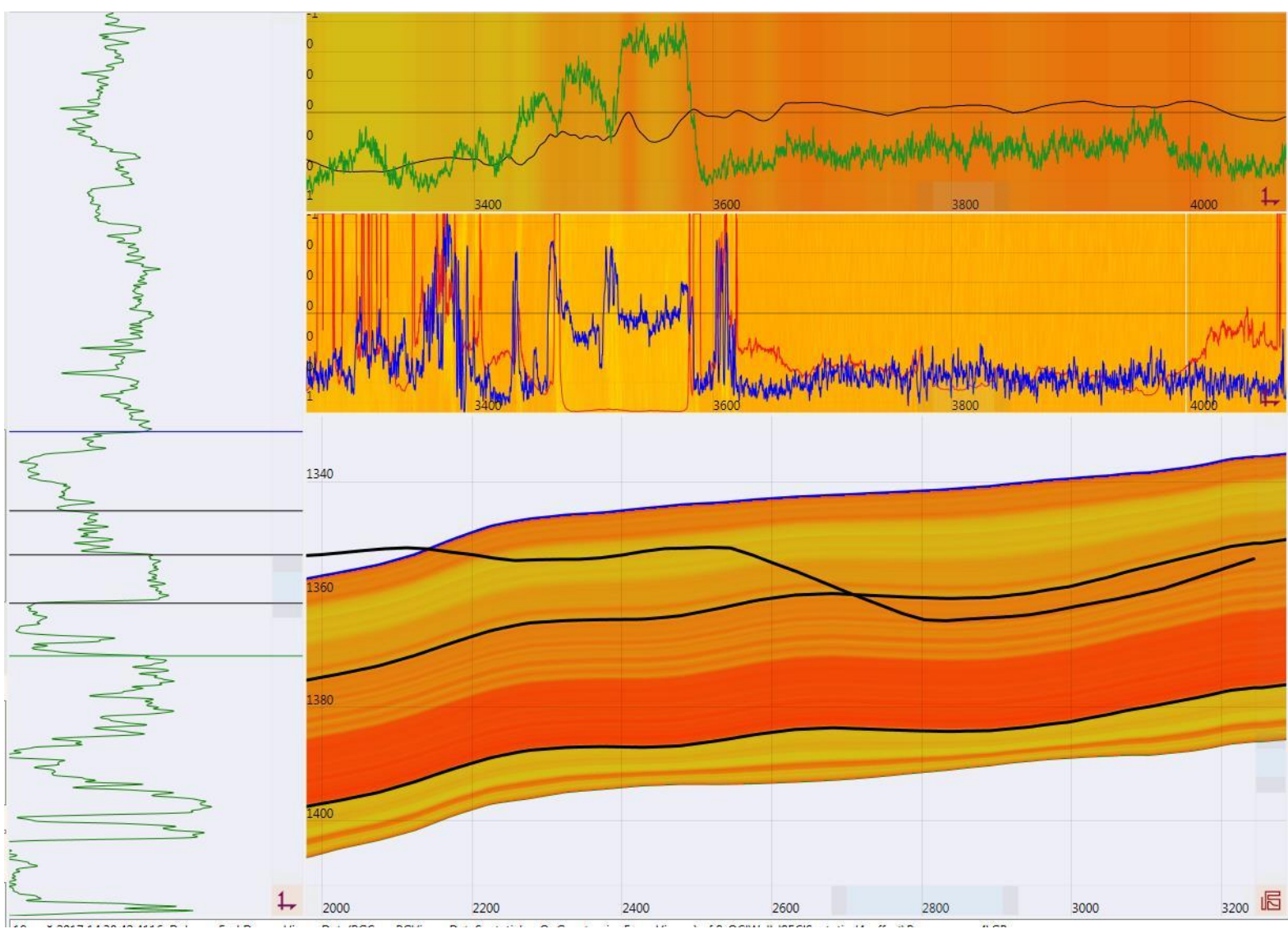

Рисунок 4. Разрез вдоль фактической траектории основного ствола 2. Распределение свойств по глинистости (ПО ПетроИнфоТех ПроСистем).

В ходе бурения горизонтальный ствол скважины пересек отложения неокомского надъяруса от кровли до подошвы.

\section{Заключение}

В настоящий момент благодаря применению специализированного программного обеспечения в ООО «ЛУКОЙЛ-Нижневолжскнефть» специалистами Общества минимизирован объем подрядных работ, большая часть построений выполняется собственными силами (группой геологического сопровождения строительства скважин). В настоящий момент в ПО ПетроИнфоТех ПроСистем общество выполняет интерпретацию сейсморазведки, проводит картопостроение для трехмерного моделирования, осуществляет межскважинную корреляцию, выполняет расчет синтетического каротажа по результатам ГИС в пробуренных скважин, осуществляет геонавигацию в режиме реального времени. 